\title{
Novel cryptic chromosomal rearrangements detected in acute lymphoblastic leukemia detected by application of new multicolor fluorescent in situ hybridization approaches
}

\author{
CONSTANZE KARST $^{1}$, MADELEINE GROSS ${ }^{1}$, DETLEF HAASE $^{2}$, ULRICH WEDDING ${ }^{3}$, \\ KLAUS HÖFFKEN $^{3}$, THOMAS LIEHR ${ }^{1}$ and HASMIK MKRTCHYAN ${ }^{1,4}$
}

\author{
${ }^{1}$ Institut für Humangenetik und Anthropologie, Kollegiengasse 10, D-07743 Jena; ${ }^{2}$ Hämatologie/Onkologie, \\ Zytogenetisches Labor 3D1.235, Georg-August-Universität, Robert-Koch-Str. 40, D-37075 Göttingen; ${ }^{3}$ Klinik und \\ Poliklinik für Innere Medizin II, Erlanger Allee 101, D-07747 Jena, Germany; ${ }^{4}$ Department of Genetic and \\ Laboratory of Cytogenetics, State University, 1 Alex Manoukian Street, Jerewan 375025, Armenia
}

Received October 10, 2005; Accepted December 2, 2005

\begin{abstract}
Routine cytogenetic analysis provides important information on diagnostic and prognostic relevance for hematological malignancies. However, it is often difficult to obtain good karyotypes, especially of cells from cases with acute lymphoblastic leukemia (ALL) because of poor morphology and spreading. Thus, detailed karyotyping can be hampered and even in case of a 'normal karyotype' according to banding cytogenetics doubts remain if the result is reliable. In order to address this problem a series of 37 ALL cases without any detectable numerical or structural chromosomal defects was selected and studied by two recently developed multicolor fluorescence in situ hybridization (FISH) approaches: 1) multitude multicolor banding (mMCB) is a FISH-banding technique, which allows the analyses of inter- and intra-chromosomal rearrangements of the whole human karyotype in one single experiment; 2) chromosome-specific subcentromere/subtelomere-specific multicolor (subCTM-)FISH applies locus-specific subtelomeric and subcentromic probes and enables the characterization of the subtelomeric and peri-centric regions of the chromosomes, not analyzable by other FISHapproaches. Thus, we detected the following recurrent cryptic chromosomal aberrations: $\operatorname{del}(12)$ (pter) [8 cases], $\operatorname{del}(9)$ (qter) [3 cases], and del(11)(pter) [2 cases]. Moreover, cryptic changes in additional nine subtelomeric and in two subcentromeric regions were observed one time, each. In summary, mMCB and subCTM were proven to be powerful
\end{abstract}

Correspondence to: Dr Thomas Liehr, Institut für Humangenetik und Anthropologie, Postfach, D-07740 Jena, Germany

E-mail: i8lith@mti.uni-jena.de

Key words: cryptic rearrangements, chromosomal breakpoints, fluorescence in situ hybridization, multitude multicolor banding, subcentromere/subtelomere-specific multicolor-FISH methods in the screening for new cryptic chromosomal aberrations, which considerably increased the accuracy of cytogenetic diagnosis.

\section{Introduction}

The classification of acute leukemia into therapeutically relevant risk categories relies on clinical parameters, as well as on the tumor cell karyotypes. Based on such data, the current cure rate has made remarkable progress in children and in adults $(1,2)$. However, the development of more reliable laboratory tests that predict patient prognosis should lead to an even more enhanced patient survival. This is especially valid and necessary in T-ALL, where no cytogenetically defined prognostic subgroups have been identified yet (3).

An integral part of the diagnosis of ALL is the cytogenetic screening for chromosomal abnormalities. In the past, routine cytogenetics identified many important karyotypic changes (4) and thus gave hints on the localization of oncogenes or tumor suppressor genes (reviewed in refs. 5 and 6). Even though the introduction of molecular cytogenetics in the last decades facilitated routine tumor cytogenetic analysis, high mitotic index and chromosomes of good quality still have importance, especially in the initial chromosome analysis. Nonetheless, the characterization of cryptic rearrangements remains problematic if standard techniques are applied, like GTGbanding combined with M-FISH (7) or SKY (8). This is mainly due to the fact that cell suspension of ALL-cases often present with only a few metaphase spreads per slide and bad chromosome morphology, i.e. short, bad shaped chromosomes with a low banding resolution. Thus, FISHbanding techniques (9) such as the multitude multicolorbanding (mMCB) (10) or approaches like the subcentromere/ subtelomere-specific multicolor (subCTM-) FISH (11) were developed to overcome these difficulties.

In the present study, we analyzed cytogenetic bone marrow preparations of 37 patients suffering from ALL; banding 
Table I. Overview of the clinical diagnosis, the age of the patient, the molecular cytogenetic result and the techniques applied in the 37 studied patients. ${ }^{a}$

\begin{tabular}{lcc}
\hline $\begin{array}{l}\text { Case (age at } \\
\text { diagnosis) }\end{array}$ & Result & Method \\
\hline
\end{tabular}

\section{T-ALL}

$1(43)$

38 45,XX[7]/38 43,XX,del(9)(q34.3)[3]/46,XX[2]*

$2(17)$

$3(28)$

4 (29)

$5(42)$

$6(30)$

$7(18)$

8 (16)

9 (21)

10 (8)

pre-T-ALL

11 (23)

12 (27)

13 (21)

B-ALL

14 (65)

15 (54)

16 (23)

17 (57)

pre-B-ALL

18 (64)

pre-B-ALL

$19(19)$

pre-B-ALL
46,XX,del(11)(p15.5)[3]/46,XX[2]*

nuc ish $11 \mathrm{p} 15.5[60 / 100]$

46,XY,del(12)(p13)[3]/46,XY[4]*

46,XY,del(12)(p13)[3]/46,XY[2]*

46,XY,del(12)(p13),t(7;17)(p22;q22)[4]/46,XY[11]*

46,XY,del(13)(q34)[3]/46,XY[5]*nuc ish 13q34[14/100]

45,XY, der(5)t(9;5;9)(9qter->9q13::5q13->5q23.1::5p13.1-

$>5 \mathrm{p} 15.2 \sim 15.3:: 5 \mathrm{q} 23.1->5 \mathrm{p} 15.2 \sim 15.3:: 5 \mathrm{q} 13-$

$>5 \mathrm{q} 23.1:: 5 \mathrm{p} 13.1->5 \mathrm{p} 15.2 \sim 15.3:: 5 \mathrm{q} 13->5 \mathrm{q} 23.1:: 9 \mathrm{p} 21-$

$>9$ pter $)$,-

9,del(11)(q14),del(14)(q12)[9]/46,XY,del(4)(p13 14),der( 5)t(18;5)(18pter->18p11.31: :5q13->5p15.2 15.3::5p12-

$>5$ pter),-9,del(11)(q14), del(14)(q12),der(18)t(18;5;9)

(18qter->18p11.31::5p15.3->5p12::9q13-

$>9$ qter)[3]/46,XY,del(5)(q34)[3]/46,XY[37]*

48,XX,der(4)?t(4;18),+mar1,+mar2 [3]/46,XX[12]*

$45, X Y,-19[8] / 46, X Y[12]^{*}$

$47, \mathrm{XY},+21[3 / 10]^{*}$

$46, X Y$, ins(5;7)(q21;p14p22),t(3;7)(p21;q11.23)[5/10]**

$\mathrm{t}(9 ; 22)(\mathrm{q} 34 ; \mathrm{q} 11)[5 / 14] * * *$

\section{$46, X Y$}

$46, X Y$

$46, \mathrm{XX}$

46,XX,del(11)(q25)[3]/46,XX[16]*

$46, \mathrm{XX}, \operatorname{del}(12)(\mathrm{p} 13)[3] / 46, \mathrm{XX}[13]^{* *}$

$46, \mathrm{XX}, \operatorname{del}(17)(\mathrm{q} 25)[3] / 46, \mathrm{XX}[8] * * *$

46,XX,del(18)(p11.31),dup(18)(q11.2)[4]/46,XX[16]****

46,XY,del(12)(p13)[3]/46,XY[7]*

$46, \mathrm{XX}$

45,XX,r(5)(p10q34),del(9)(p24),-21[3]/

46,XX,del(4)(q31),del(5)(q21)[3]/46,XX[2]*

46,XX,del(9)(q34)[3]/46,XX[3]*

46,XX,del(11)(p15.5)[3]/46,XX[7]*

46,XX,del(22)(q13.33)[3]/46,XX,-22[3]/46,XX[4]**
mMCB; LSI MLL; subCTM \#2, \#3, \#4, \#5, \#6, \#7, \#9*,\#11,\#12,\#13,\#14,\#16,\#19,\#22

mMCB; subCTM \#11*; LSI BCR/ABL-ES

mMCB; subCTM \#12*

mMCB; $\operatorname{subCTM~\# 5,\# 7,\# 12*~}$

mMCB*; M-FISH; subCTM \#1, \#2, \#3, \#4, \#5,\#6, \#7, \#9, \#11, \#12, \#13, \#14, \#16, \#17, \#18, \#21, \#22

mMCB*; LSI-MLL

$\mathrm{mMCB}^{*} ; \mathrm{SKY}^{*}$

mMCB; M-FISHM; LSI MLL; subCTM \#1,\#2,\#3, $\# 4 *$, \#5, \#6, \#7, \#11,\#12,\#21, \#22

mMCB*; LSI MLL; subCTM \#5,\#7, \#11, \#18,\#19

mMCB; M-FISH*; LSI MLL; LSI

BCR/ABL-ES***; MCB \#3/\#5/\#7**;

subCTM \#2, \#3, \#4, \#9, \#14, \#17, \#18, \#19, \#21, \#22 mMCB; SKY; M-FISH; M-TEL; WCP \#5; LSI-MLL $\mathrm{mMCB}$

mMCB; subCTM \#4, \#7, \#12,\#19

mMCB; LSI MLL; $\operatorname{subCTM~\# 1,~\# 2,~\# 4,~\# 5,~}$ $\# 7, \# 9, \# 11 *, \# 12 * *, \# 13, \# 14, \# 17 * * *$, $\# 18 * * * *, \# 19, \# 21, \# 22$

mMCB; $\operatorname{subCTM~\# 12*~}$ mMCB; subCTM \#1, \#4, \#5, \#6, \#9, \#11, $\# 12, \# 13, \# 14, \# 19, \# 21$

mMCB*; MCB \#5; LSI MLL; WCP \#5; M-TEL

mMCB*; LSI MLL

mMCB; LSI MLL; subCTM \#11* \#22** 
Table I. Continued.

\begin{tabular}{|c|c|c|}
\hline $\begin{array}{l}\text { Case (age at } \\
\text { diagnosis) }\end{array}$ & Result & Method \\
\hline \multicolumn{3}{|l|}{ B-ALL } \\
\hline $\begin{array}{l}20(6) \\
\text { pre-B-ALL }\end{array}$ & $46, X X$ & $\mathrm{mMCB}$ \\
\hline $\begin{array}{l}21(51) \\
\text { pre-pre-B-ALL }\end{array}$ & $\sim 89, \mathrm{XXXX}[3] / 46, \mathrm{XX}[7]^{*}$ & mMCB* \\
\hline $\begin{array}{l}22(17) \\
\text { biphen. ALL/ } \\
\text { B-ALL }\end{array}$ & $\begin{array}{l}47, \mathrm{XX},+8, \operatorname{del}(4)(\mathrm{p} 16.3)[6 / 15]^{*} \\
47, \mathrm{XX},+8, \operatorname{del}(12)(\mathrm{p} 12)[6 / 17]^{* *} \\
47, \mathrm{XY},+8, \operatorname{del}(5)(\mathrm{q} 34), \mathrm{t}(5 ; 7)(\mathrm{q} 31 ; \mathrm{p} 12)[8 / 20]^{* * *}\end{array}$ & $\begin{array}{l}\text { mMCB***; M-FISH**; LSI MLL; WCP \#5; } \\
\operatorname{subCTM~\# 4*,\# 5,\# 6,\# 7,\# 12**,\# 19,\# 21~}\end{array}$ \\
\hline \multicolumn{3}{|l|}{ C-ALL } \\
\hline $23(49)$ & 46,XY,der(1)dup(1pter-q44::q12qter)[3]/46,XY[7]* & mMCB; M-FISH; WCP \#1; MCB \#1* \\
\hline $\begin{array}{l}24(22) \\
\text { FAB L3 }\end{array}$ & $45, \mathrm{XY}, \operatorname{del}(9)(\mathrm{q} 34), \operatorname{del}(12)(\mathrm{p} 13),-22[3] / 46, \mathrm{XY}[3]^{*}$ & mMCB*; subCTM \#12 \\
\hline $25(19)$ & $\begin{array}{l}46, \mathrm{XY}, \operatorname{del}(12)(\mathrm{p} 13.33)[3] / 46, \mathrm{XY}[3]^{*} \\
\text { nuc ish } 12 \mathrm{p} 13.33[9 \%]\end{array}$ & mMCB; subCTM \#4,\#7,\#12*,\#22 \\
\hline $26(40)$ & $45, X X, \operatorname{del}(5)(q 32),-22[3] / 46, X X[5]^{*}$ & mMCB*; M-FISH \\
\hline $27(19)$ & $46, X Y$ & $\begin{array}{l}\text { mMCB; M-TEL; MCB \#5; WCP \#5; WCP } \\
\text { \#9; LSI-MLL }\end{array}$ \\
\hline $28(28)$ & $46, X Y$ & mMCB; SKY; LSI BCR/ABL-ES \\
\hline $29(48)$ & $46, X Y$ & mMCB; subCTM \#5,\#7 \\
\hline $30(27)$ & $46, X Y$ & mMCB; LSI BCR/ABL-ES \\
\hline \multicolumn{3}{|l|}{ ALL } \\
\hline $31(67)$ & $46, X X$ & $\mathrm{mMCB}$ \\
\hline $32(55)$ & $46, X X$ & $\mathrm{mMCB}$ \\
\hline $33(14)$ & $46, X Y$ & mMCB; MCB12; subCTM\#12 \\
\hline $34(3)$ & $46, X X$ & mMCB; subCTM \#9 \\
\hline $35(57)$ & $46, X X$ & $\mathrm{mMCB}$ \\
\hline $36(34)$ & $46, X X$ & $\mathrm{mMCB}$ \\
\hline $37(42)$ & $46, X X$ & mMCB; LSI-MLL \\
\hline
\end{tabular}

aThe probe sets leading to the identification of a previously cryptic rearrangement are in bold in the last column. The asterisks indicate which FISH-results was/were used for the karyotypic formula and determination of approximate clone sizes in the center column.

cytogenetics revealed no cytogenetic changes in these cases. After application of molecular cytogenetics, we detected cryptic aberrations in 21 of these cases $(\sim 57 \%)$.

\section{Materials and methods}

Studied cases and banding cytogenetics. Bone marrow cells of 37 patients were investigated for chromosomal changes in connection with an acute lymphoblastic leukemia (ALL). Cells were taken into short-term cell culture and chromosomes were prepared and GTG-banded according to standard protocols (12). Metaphase spreads (10 to 20) were available for cytogenetic evaluation on a banding level of 180-250 bands per haploid karyotype. Thirteen patients suffered from T-ALL, 9 had a B-ALL (4 including pre-B-ALL and 1 pre-pre-B-ALL case), 8 patients had a C-ALL and 7 presented a clinically not closer classified ALL (Table I). Apart from cases 10, 20 and 34, all were adult ALL cases.

Molecular cytogenetics. Fluorescence in situ hybridization (FISH) was performed according to standard protocols (13) using the commercially available probe LSI-MLL (11q23, Vysis) and/or LSI BCR-ABL-ES to exclude a cryptic 'Phildelphia-translocation' $\mathrm{t}(9 ; 22)(\mathrm{q} 34 ; \mathrm{q} 11)$. M-FISH or 
SKY (14), mMCB (10), MCB (15) and subCTM-FISH (11) or M-TEL-FISH (16) were done as previously described. The results were evaluated on a fluorescence microscope equipped with a CCD-camera and an image analysis system (MetaSystems, Altlussheim, Germany). Metaphase spreads (5 to 10) were evaluated per case and probe (set) used. In some cases there was not enough cell suspension available to apply all probe sets (Table I).

\section{Results}

The routine banding cytogenetics detected no acquired chromosomal changes in the 37 ALL cases in the present study (Table I). The cases were studied by mMCB (10) at first. According to the $\mathrm{mMCB}$ results, additional studies were performed. M-FISH or SKY (14) were used when the mMCB result had to be verified for possible inter-chromosomal exchanges ( 7 cases). In case 10 , it was necessary to confirm and substantiate mMCB also by single MCB experiments (15). If only sparse cell suspension was available, chromosomespecific subCTM-FISH probe sets (11) were selected according to the mMCB results; in cases with sufficient test specimens subCTM-FISH probe sets for (almost) all chromosomes and also the LSI MLL probe were applied (e.g. cases 1, 5, 8, 14, 16, and 22). Cases 11 and 27 were tested by M-TEL-FISH (16) for cryptic subtelomeric rearrangements.

In the aforementioned cytogenetic preparations of 37 patients suffering from ALL (Table I), molecular cytogenetics detected cryptic aberrations in 19 of the cases $(\sim 50 \%)$. They were divided into four groups: 1) such cases with cytogenetic changes detectable by banding cytogenetics, however, not detected in these cases, due to too few evaluated/evaluable metaphase spreads and/or too low banding resolution, i.e. in cases 7-10, 21, 23 and 26 (19\% of 37 cases); 2) cases with by banding cytogenetics undetectable, i.e. real cryptic changes in cases $2-4,6,14-15,18$, and $25(21 \%)$; 3) cases presenting a mixture of group 1 and group 2 aberrations: cases 1, 5, 17, 19, 22 and 24 (16\%); and, 4) those cases without any detectable karyotypic changes after application of $\mathrm{mMCB}$ and/or the other molecular cytogenetic probes (cases 11-13, $16,20,27-37=44 \%$ ).

The undetected clonal changes found during banding cytogenetics for group 1 were: hypodiploidy [case 1], hyperploidy [case 21], duplication of the long arm of chromosome 1 [case 23], translocation $\mathrm{t}(4 ; 18)$ with two additional marker chromosomes, both changes detected in subCTM-FISH exclusively, and thus, not closer characterizable [case 8], trisomy 8 [case 22], monosomy 19 [case 9] and 22 [cases 19 and 24] and complex [case 17] and highly complex rearrangements [cases 7 and 10] (Fig. 1 and Fig. 2).

The following recurrent cryptic chromosomal aberrations were detected in group 2: del(12)(p13) [8 cases], $\operatorname{del}(9)(\mathrm{q} 34.3)$ [ 3 cases], and del(11)(p15.5) [2 cases]. Moreover, the following additional cryptic changes were detected for one case, each. However, they were at least 3 times present per case, which is the definition for clonality: del(4)(p16.3) [case 22], del(4)(q31) [case 17], del(5)(q11.2-q11.2) [case 17], del(5)(q34) [case 22], $\operatorname{del}(13)(\mathrm{q} 34)$ [case 6], del(17)(q25) [case 14], del(18)(p11.31) [case 14], del(22)(q13.33) [case 19], dup(18)(q11.2) [case 14], $\mathrm{t}(7 ; 17)(\mathrm{p} 22 ; \mathrm{q} 22)$ [case 5]. In peripheral blood of 5 normal controls, similar changes were not observed with the applied subtelomeric and subcentromeric probes; the metaphase-FISH cutoff for artificial signal loss of the used probes was always 1 in 20 metaphases or below.

\section{Discussion}

In the present study, the mMCB technique (10) combined with subCTM-FISH (11) and the other aforementioned approaches (Table I) were applied to study chromosomes according to banding cytogenetics karyotypically normal bone-marrow probes of 37 ALL-patients. This is the first systematic study using this kind of methodology in leukemia research.

The FISH-banding technique (9) multitude multicolor banding (mMCB) was chosen as it has proven its ability and reliability in previous studies and is the only one which has been systematically adjusted with other FISH-techniques (17-25). However, as all (multicolor) FISH techniques based on whole or partial chromosome painting probes, also mMCB is not completely reliable concerning the subtelomeric and subcentromeric chromosomal regions. As this study was aimed to examine as comprehensively as possible all chromosomal sub-regions, subCTM-FISH was applied additionally. However, as subCTM can presently only be used chromosome-wise, a large amount of cell suspension is necessary for this kind of analysis. One has to admit that sufficient test specimens were not available in all cases and thus, the comprehensiveness of the present analysis was hampered. However, this problem is a well-known one in tumor cytogenetic studies (26).

Group 1/group 3: cases with cytogenetic changes detectable by banding cytogenetics. Twenty-one of 37 of the studied cases $(\sim 57 \%)$ presented cryptic aberrations. However, in 12 of the aberrant cases (32\%; cases of groups 1 and 3 ) the cytogenetic aberrations could have been detected in banding cytogenetics, if more and/or better metaphase spreads would have been available for evaluation.

Hypodiploidy or hyperploidy as detected in cases 1 and 21, respectively, are well-known findings in two different small subgroups of adult ALL $(27,28)$. The translocation $t(4 ; 18)$ in case 8 could not be described in more detail and a translocation event in which both chromosomes would have been involved has not been previously described in ALL (4). Trisomy 8 [case 22] and gain of the long arm of chromosome 1 [case 23] were previously reported in ALL (4). Monosomies of chromosomes 19 [case 9] or 22 [cases 19 and 24] were also not previously reported in acute leukemia, while complex [case 17] and highly complex rearrangements [cases 7 and 10] are known to appear and to be associated with an adverse prognosis in ALL $(4,29,30)$.

Thus, a substantial part of cases diagnosed as karyotypical normal seem to have detectable chromosomal rearrangements when reanalyzed by molecular cytogenetics. This seems to be a more general problem, as our cases were recruited from two different German centers (Jena, Göttingen), both headed by well-experienced cytogenetists.

Group 2/group 3: cases with cryptic cytogenetic changes. In a control study using all 24 subCTM-probe sets on peripheral blood of 5 normal controls artificial deletion of the applied 


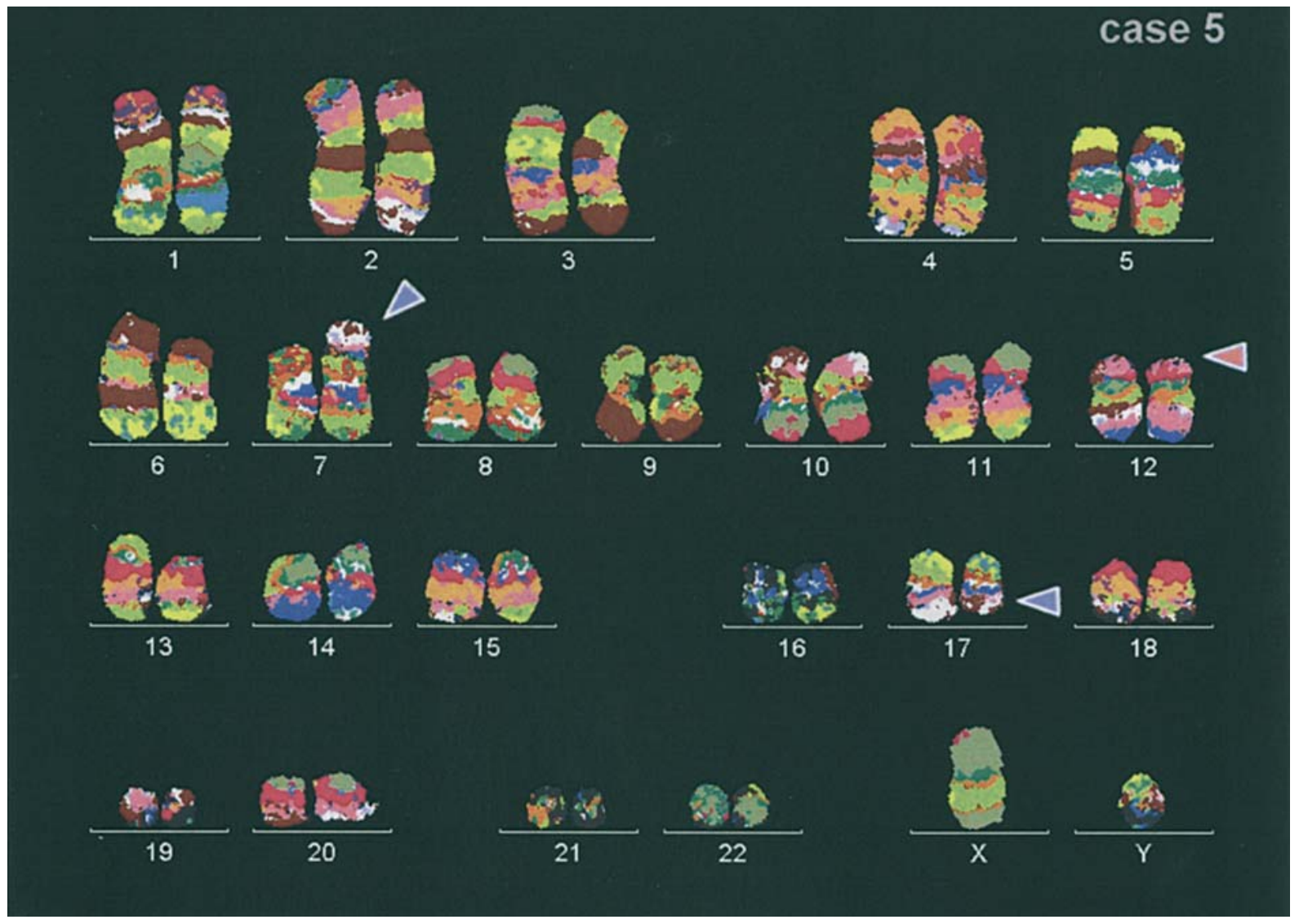

Figure 1. Representative multitude multicolor banding (mMCB) result of case 5 in pseudocolor depiction. The del(12)(p13) is marked with a red arrowhead, the $\mathrm{t}(7 ; 17)$ with two blue arrowheads.

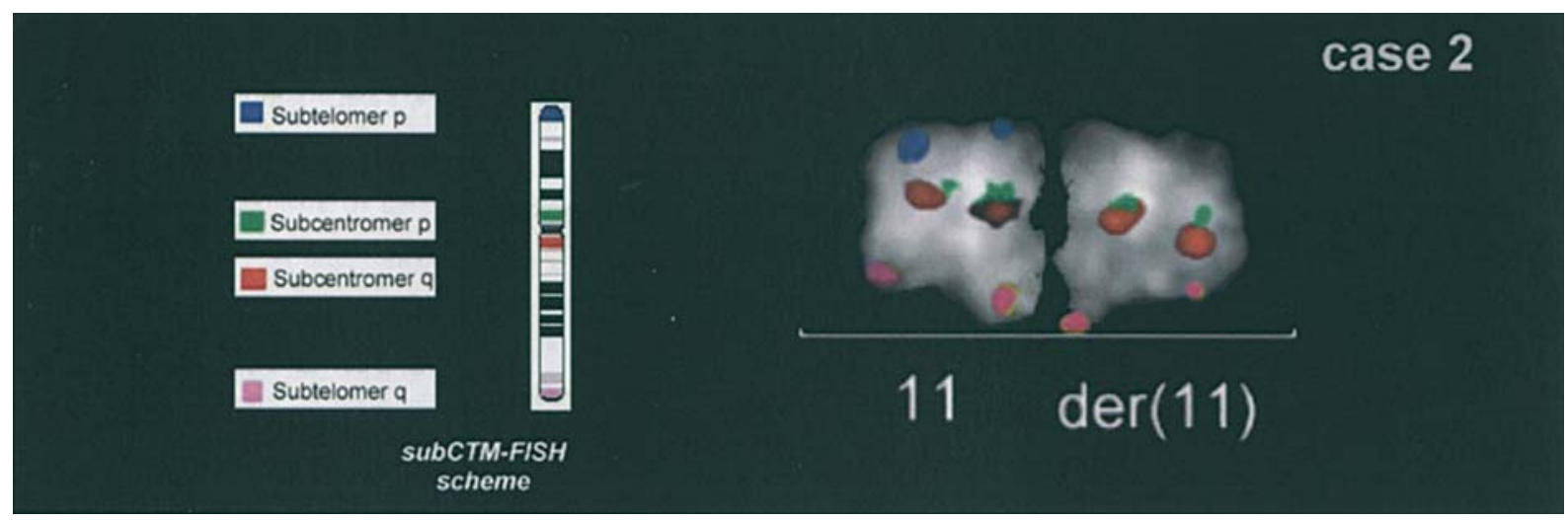

Figure 2. Results of subCTM FISH probe set 11 applied in case 2. On the left, chromosome 11 is depicted as an ideogram with the applied color code for subCTM-FISH given beside it. The color channel for the whole chromosome painting probe is not depicted here, however, both chromosome 11 and derivative chromosome 11 were stained completely.

subtelomeric and subcentromeric probes was observed in 0 to 1 out of 20 metaphases, each. Thus, the cut-off for signal loss was determined at 2/20 mitosis. According to this definition, recurrent cryptic chromosomal aberrations were detected as terminal deletions in 12p13 [cases 3, 4, 5, 14, 15, 22, 24 and 25], 9q34.3 [cases 1, 18 and 24], and 11p15.5 [cases 2 and 19] in 12 of the 37 studied cases (32\%).

Indications on involvement of $12 p$ in ALL were previously found (31); interestingly in the present and in the previous study (31) no correlation with the ALL-subtype was detectable.
Thus, the frequency of its appearance ( 20\%) may be interpreted as a hint on an early event during leukemogenesis.

While terminal deletions $9 \mathrm{q}$ are well-known in AML (acute myelogenous leukemia) (32), they are rarely described in ALL and then interpreted as interstitial deletions in $9 q(4,33)$. However, the application of the subtelomeric probes in $9 \mathrm{q}$ encovered terminal deletions in $9 \mathrm{q} 34$ in one case of adult TALL, B-ALL and C-ALL, each. This observation was not due to 'Philadelphia-translocations' between chromosomes 9 and 22 , as excluded by mMCB and subCTM-FISH. 
The deletion 11p15.5 has not been described before in ALL - here, it was detected in a T-ALL (case 2) and a pre-BALL (case 19). For case 2, the subclone with a deletion 11pter was proven by interphase FISH to be present even in $60 \%$ of the cells. Deletions of $11 \mathrm{p} 15$ were previously discussed only in connection with treatment-related leukemia; however, cases 2 and 19 were not treated prior to cytogenetics (34).

For the additionally detected unique cryptic changes, the following data were available in the literature: involvement of the terminal region of $5 q$ in rearrangements, as detected in case 22 , were the first cryptic subtelomeric aberrations detected in leukemia (35). Not previously reported were a del(4)(p16.3) [case 22] a del(4)(q31) [case 17], a del(5)(q11.2-q11.2) [case 17], a del(13)(q34) [case 6], a del(18)(p11.31) [case 14], a del(17)(q25) [case 14], a $\operatorname{del}(22)(q 13.33)$ [case 19], a $\operatorname{dup}(18)(\mathrm{q} 11.2)$ [case 14] or a $\mathrm{t}(7 ; 17)(\mathrm{p} 22 ; \mathrm{q} 22)$ [case 5], however, an involvement of the p53 gene in the leukemogenesis of the latter case could not be excluded.

Some of the clonal cryptic rearrangements were observed concurrently with others [cases 5, 14, 17, 19, 22, and 24], or with larger rearrangements in the same patient (group 3). However, it is well-known that ALL tend to have complex chromosomal aberrations (see also case 7). The aberrations were detected by mMCB and/or by different subCTM-FISH experiments. Thus, it was not always possible to describe the aberrations and their frequencies in relation to each other; for cases $10,14,19$, and 22 the aberrations were suspected after mMCB, but clearly visible only in subCTM-FISH. Thus, in these cases the clone sizes were estimated only by chromosome-specific subCTM-FISH experiments (Table I). Due to lack of material it was possible only in exceptional cases to prove the subclone presence in interphase-FISH [cases 2, 6, and 25].

Nonetheless, it can be stated that the application of up to now not available approaches for molecular cytogenetic characterization gave hints on possible new critical regions for ALL leukemogenesis and progression, which have to be confirmed and further studied in future. None of the new cryptic rearrangements of group 2 was detected either in the childhood ALL-cases of the present study [cases 10, 20, and 34] or in a recent study on childhood ALL (36).

Group 4: cases without detectable cryptic cytogenetic changes. In 16 of the $37(44 \%)$ studied cases, no chromosomal aberrations were detected by $\mathrm{mMCB}$ or $\mathrm{mMCB}$ plus other approaches. However, in case 12, 20, 31, 32, 35 and 36 only mMCB could be performed as sufficient cell suspension for subCTM-studies was not available. Thus, one cannot be sure if aberrations would have been detected if more probes could have been applied.

In conclusion, the present study proved the usefulness of the mMCB-approach combined with subCTM-FISH in tumor cytogenetics for identifying chromosomal rearrangements that cannot be recognized by conventional GTG-banding. Up to present GTG-banding, often in combination with M-FISH or SKY, is the gold-standard in leukemia diagnostics. This and previous studies $(26,35)$ showed that these methods alone cannot lead to comprehensive cytogenetic results. mMCB and subCTM-FISH could be the new molecular-cytogenetic standards for the determination of cytogenetic rearrangements.

\section{Acknowledgements}

Supported in part by the Deutsche Krebshilfe/Mildred Scheel Stiftung für Krebsforschung (70-3125-Li1), the INTAS (AISbl 03-51-4060), the IZKF together with the TMWFK (TP 3.7 and B307-04004), the DFG (436 ARM 17/2/04) and the UICC (ICR/05/030). We thank Dr I. Loncarevic and Dr A. Weise (Jena, Germany) for providing cell suspension of clinical cases. M-TEL FISH probe set was kindly provided by Dr Lyndal Kearney (London, UK).

\section{References}

1. Pui $\mathrm{CH}$ and Evans WE: Acute lymphoblastic leukemia. N Engl J Med 339: 605-615, 1998.

2. Harrison CJ: Acute lymphoblastic leukaemia. Best Pract Res Clin Haematol 14: 593-607, 2001.

3. Roman-Gomez J, Jimenez-Velasco A, Agirre X, Prosper F, Heiniger $A$ and Torres A: Lack of $\mathrm{CpG}$ island methylator phenotype defines a clinical subtype of T-cell acute lymphoblastic leukemia associated with good prognosis. J Clin Oncol 23: 7043-7049, 2005.

4. Hurlet JL: Atlas of Genetics and Cytogenetics in Oncology and Haematology. http://www.infobiogen.fr/services/chromcancer/ anomalies/anomliste.html, 2005.

5. Armstrong SA and Look AT: Molecular genetics of acute lymphoblastic leukemia. J Clin Oncol 23: 6306-6315, 2005.

6. De Keersmaecker K, Marynen P and Coolsi J: Genetic insights in the pathogenesis of T-cell acute lymphoblastic leukemia. Haematologica 90: 1116-1127, 2005.

7. Speicher MR, Gwyn Ballard S and Ward DC: Karyotyping human chromosomes by combinatorial multi-fluor FISH. Nat Genet 12: 368-375, 1996.

8. Schröck E, Du Manoir S, Veldman T, Schoell B, Wienberg J, Ferguson-Smith MA, Ning Y, Ledbetter DH, Bar-Am I, Soenksen D, Garini Y and Ried T: Multicolor spectral karyotyping of human chromosomes. Science 273: 494-497, 1996.

9. Liehr T, Heller A, Starke H and Claussen U: FISH banding methods: applications in research and diagnostics. Expert Rev Mol Diagn 2: 217-225, 2002.

10. Weise A, Heller A, Starke H, Mrasek K, Pool-Zobel BL, Kuechler A, Claussen U and Liehr T: Multitude multicolor chromosome banding (mMCB) - a comprehensive one-step multicolor FISH banding method. Cytogenet Genome Res 103: 34-39, 2003.

11. Gross M, Starke H, Trifonov V, Claussen U, Liehr T and Weise A: A molecular cytogenetic study of chromosome evolution in chimpanzee. Cytogenet Genome Res (In press).

12. Verma RS and Babu A: Human Chromosomes, Principles and Techniques. 2nd edition, McGraw-Hill, Inc., New York, 1995.

13. Liehr T, Thoma K, Kammler K, Gehring C, Ekici A, Bathke KD, Grehl $\mathrm{H}$ and Rautenstrauss B: Direct preparation of uncultured EDTA-treated or heparinized blood for interphase FISH analysis. Appl Cytogenet 21: 185-188, 1995.

14. Liehr T, Starke H, Weise A, Lehrer H and Claussen U: Multicolor FISH probe sets and their applications. Histol Histopathol 19: 229-237, 2004.

15. Liehr T, Heller A, Starke H, Rubtsov N, Trifonov V, Mrasek K, Weise A, Kuechler A and Claussen U: Microdissection-based high resolution multicolor banding for all 24 human chromosomes. Int J Mol Med 9: 335-339, 2002.

16. Brown J, Saracoglu K, Uhrig S, Speicher MR, Eils R and Kearney L: Subtelomeric chromosome rearrangements are detected using an innovative 12-color FISH assay (M-TEL). Nat Med 7: 497-501, 2001.

17. Starke H, Raida M, Trifonov V, Clement JH, Loncarevic IF, Heller A, Bleck C, Nietzel A, Rubtsov N, Claussen U and Liehr T: Molecular cytogenetic characterization of an acquired minute supernumerary marker chromosome as the sole abnormality in a case clinically diagnosed as atypical Philadelphia-negative chronic myelogenous leukaemia. Br J Haematol 113: 435-438, 2001.

18. Tönnies H, Stumm M, Wegner R-D, Chudoba I, Kalscheur V and Neitzel H: Comparative genomic hybridization based strategy for the analysis of different chromosome imbalances detetced in conventional cytogenetic diagnostic. Cytogenet Cell Genet 93: 188-194, 2001. 
19. Stumm M, Musebeck J, Tönnies H, Volleth M, Lemke J, Chudoba I and Wieacker P: Partial trisomy 9p12p21.3 with a normal phenotype. J Med Genet 39: 141-144, 2002.

20. Starke H, Senger G, Kossakiewicz M, Tittelbach H, Rau D, Rubtsov N, Trifonov V, Heller A, Hartmann I, Claussen U and Liehr T: Maternal insertion of 18q11.2-q12.2 in 18p11.3 of the same chromosome analysed by microdissection and multicolour banding (MCB). Prenat Diagn 21: 1049-1052, 2001.

21. Starke H, Seidel J, Henn W, Reichardt S, Volleth M, Stumm M, Behrend C, Sandig KR, Kelbova C, Senger G, Albrecht B, Hansmann I, Heller A, Claussen U and Liehr T: Homologous sequences at human chromosome 9 bands p12 and q13-21.1 are involved in different patterns of pericentric rearrangements. Eur J Hum Genet 10: 790-800, 2002.

22. Dufke A, Walczak C, Liehr T, Starke H, Trifonov V, Rubtsov N, Schoning M, Enders $\mathrm{H}$ and Eggermann T: Partial tetrasomy 12 pter-12p12.3 in a girl with Pallister-Killian syndrome: extraordinary finding of an analphoid, inverted duplicated marker. Eur J Hum Genet 9: 572-576, 2001.

23. Liehr T, Weise A, Heller A, Starke H, Mrasek K, Kuechler A, Weier HU and Claussen U: Multicolor chromosome banding (MCB) with YAC/BAC-based probes and region-specific microdissection DNA libraries. Cytogenet Genome Res 97: 43-50, 2002.

24. Trappe R, Bohm D, Kohlhase J, Weise A, Liehr T, Essers G, Meins M, Zoll B, Bartels I and Burfeind P: A novel familyspecific translocation $\mathrm{t}(2 ; 20)(\mathrm{p} 24.1 ; \mathrm{q} 13.1)$ associated with recurrent abortions: molecular characterization and segregation analysis in male meiosis. Cytogenet Genome Res 98: 1-8, 2002.

25. Weise A, Starke H, Heller A, Tönnies H, Volleth M, Stumm M, Senger G, Nietzel A, Claussen U and Liehr T: Chromosome 2 aberrations in clinical cases characterised by high resolution multicolour banding and region-specific FISH probes. J Med Genet 39: 434-439, 2002.

26. Heller A, Loncarevic IF, Glaser M, Gebhart E, Trautmann U, Claussen U and Liehr T: Breakpoint differentiation in chromosomal aberrations of hematological malignancies: Identification of 33 previously unrecorded breakpoints. Int $\mathrm{J}$ Oncol 24: 127-136, 2004.

27. Harrison CJ, Moorman AV, Broadfield ZJ, Cheung KL, Harris RL, Reza Jalali G, Robinson HM, Richards SM, Barber KE, Mitchell CD, Eden TO, Hann IM, Hill FG, Kinsey SE, Gibson BE, Lilleyman J, Vora A, Goldstone AH, Franklin IM, Durrant J and Martineau M: Childhood and adult leukaemia working parties: Three distinct subgroups of hypodiploidy in acute lymphoblastic leukaemia. Br J Haematol 125: $552-559,2004$.
28. Faderl S, Kantarjian HM, Talpaz M and Estrov Z: Clinical significance of cytogenetic abnormalities in adult acute lymphoblastic leukemia. Blood 91: 3995-4019, 1998

29. Shivakumara S, Mathew S, Dalton J, Chandy M and Srivastava A: A complex karyotype involving chromosomes $3,6,11,12$, and 22 in adult acute lymphoblastic leukemia. Leuk Lymphoma 43: 1673-1677, 2002.

30. Jarosova M, Holzerova M, Mihal V, Lakoma I, Divoky V, Blazek B, Pospisilova D, Hajduch M, Novak Z, Dusek L, Koptikova J, Poulsen TS and Indrak K: Complex karyotypes in childhood acute lymphoblastic leukemia: cytogenetic and molecular cytogenetic study of 21 cases. Cancer Genet Cytogenet 145: 161-168, 2003.

31. Streubel B, Sauerland C, Heil G, Freund M, Bartels H, Lengfelder E, Wandt H, Ludwig WD, Nowotny H, Baldus M, Grothaus-Pinke B, Buchner T and Fonatsch C: Correlation of cytogenetic, molecular cytogenetic, and clinical findings in 59 patients with ANLL or MDS and abnormalities of the short arm of chromosome 12. Br J Haematol 100: 521-533, 1998

32. Catovsky D and Swansbury J: Del(9q) acute myeloid leukaemia: clinical and cytological characteristics and prognostic implications - response to Catovsky and Swansbury. Br J Haematol 130: 969, 2005.

33. Ferrara F, Scognamiglio M, Di Noto R, Schiavone EM, Poggi V, Fiorillo A, Libertini R, Vicari L, Del Vecchio L and Sebastio L: Interstitial 9q deletion is associated with CD7+ acute leukemia of myeloid and T lymphoid lineage. Leukemia 10: 1990-1992, 1996.

34. Huret JL: 11p15 rearrangements in treatment related leukemia. Atlas Genet Cytogenet Oncol Haematol. October 2003. URL: http://www.infobiogen.fr/services/chromcancer/Anomalies/11p 15TreatRelLeukID1299.html

35. Brown J, Jawad M, Twigg SR, Saracoglu K, Sauerbrey A, Thomas AE, Eils R, Harbott $J$ and Kearney L: A cryptic $\mathrm{t}(5 ; 11)(\mathrm{q} 35 ; \mathrm{p} 15.5)$ in 2 children with acute myeloid leukemia with apparently normal karyotypes, identified by a multiplex fluorescence in situ hybridization telomere assay. Blood 99: 2526-2531, 2002.

36. Poppe B, Cauwelier B, Van Limbergen H, Yigit N, Philippe J, Verhasselt B, De Paepe A, Benoit Y and Speleman F: Novel cryptic chromosomal rearrangements in childhood acute lymphoblastic leukemia detected by multiple color fluorescent in situ hybridization. Haematologica 90: 1179-1185, 2005. 